\title{
Amperometric Hydrocarbon Sensor Using Difference in Electrode Catalysis for Monitoring Exhaust Gas from Internal Combustion Engines
}

\author{
Tatsumi ISHIHARA, * Koji KaBEMURA, Madoka FuKuYAMA, Atanu DuTTA, \\ Hiroyasu NISHIGUCHI, and Yusaku TAKITA
}

\author{
Department of Applied Chemistry, Faculty of Engineering, Oita University (Dannoharu 700, Oita 870-1192, Japan)
}

Received November 18, 2002 ; Accepted February 13, 2003

\begin{abstract}
Amperometric hydrocarbon sensor based on the oxygen pumping current was studied for monitoring hydrocarbon in exhaust gas. It was found that the oxygen pumping current through the sensor using $\mathrm{La}_{0.9} \mathrm{Sr}_{0.1} \mathrm{Ga}_{0.8} \mathrm{Mg}_{0.2} \mathrm{O}_{3}$ electrolyte at $1 \mathrm{~V}$ application monotonically increased with $\mathrm{C}_{3} \mathrm{H}_{6}$ concentration, but hardly depends on oxygen concentration when $\mathrm{Pt}$ and $\mathrm{SnO}_{2}$ were used for the active and the inactive electrode for oxidation, respectively. The oxygen pumping current of the developed sensor under $1 \mathrm{~V}$ application is hardly changed by coexisting $\mathrm{CO}$ and $\mathrm{H}_{2} \mathrm{O}$. Consequently, the developed amperometric hydrocarbon sensor can detect hydrocarbon with high selectivity.
\end{abstract}

Key Words : Hydrocarbon Sensor, Amperometric Sensor, Exhaust Gas Monitoring

\section{Introduction}

Since nitrogen oxide $\left(\mathrm{NO}_{\mathrm{x}}\right)$ and an unburned fuel in the exhaust gas from an internal combustion engine in vehicles cause the severe environment destruction, $\mathrm{NO}_{\mathrm{x}}$ and hydrocarbon is simultaneously removed by using three-way catalyst at present. However, recently, there is a strong demand for monitoring the degradation of the three-way catalyst activity. In order to monitor the degradation of the activity of three-way catalyst, it is reported that the comparison of the response from a couple of oxygen sensor which set before and after the three-way catalyst can be used. ${ }^{1,2)}$ However, if hydrocarbon can be directly detected, it is expected that the more accurate monitoring will be achieved since the unremoved hydrocarbon is observed at the initial stage of degradation of the three-way catalyst activity. In addition, recently, the emission of the hydrocarbon just after start-up of engines becomes problem and monitoring the amount of hydrocarbon emission at so-called "cold start" stage is also requested. Therefore, development of the hydrocarbon sensor for monitoring exhaust gas from the internal combustion engines is an important subject at present. There are many coexisting gases such as $\mathrm{H}_{2} \mathrm{O}, \mathrm{CO}$, and $\mathrm{CO}_{2}$ in exhaust gas. Also, the oxygen partial pressure always changes in according with the operating mode of engines. Therefore, high selectivity and stability is requested for the sensor used for monitoring hydrocarbon in exhaust gas.

At present, a solid electrolyte type sensor using mixed potential, which is based on the difference in the electrode catalytic activity, is generally investigated for this purpose. ${ }^{3,4)}$ However, mixed potential is not monotonically increased with increasing the hydrocarbon concentration. Recently, Hibino et al proposed the amperometric type hydrocarbon sensor consisting of two YSZ electro- lyte plates, namely one is the detection YSZ electrolyte plate and the other is the pumping one." On this sensor, it is reported that the concentration of hydrocarbon in wider concentration can be detected based on the oxygen pumping current. However, this sensor is complicated in structure and reproducibility is rather poor. In this study, amperometric type hydrocarbon sensor using a single electrolyte plate was investigated based on a difference in catalytic and/or electrocatalytic oxidation of electrode. Since difference in oxidation activity of electrode became more significant, it is expected that the decrease in operating temperature is effective for increasing sensitivity as well as shorting the start-up time.

\section{Experimental}

Figure 1 shows the schematic view of the sensor used in this study. $\mathrm{La}_{0.9} \mathrm{Sr}_{0.1} \mathrm{Ga}_{0.8} \mathrm{Mg}_{0.2} \mathrm{O}_{3}$ (LSGM) for the electrolyte was prepared by the conventional powder mixing method by using $\mathrm{La}_{2} \mathrm{O}_{3}, \mathrm{SrCO}_{3}, \mathrm{Ga}_{2} \mathrm{O}_{3}$, and $\mathrm{MgO}^{6}$ ). The powder mixture was precalcined at $1273 \mathrm{~K}$ for $6 \mathrm{~h}$ and then final sintering was performed at $1773 \mathrm{~K}$ after making disks with isostatic press (400 MPa). The thickness

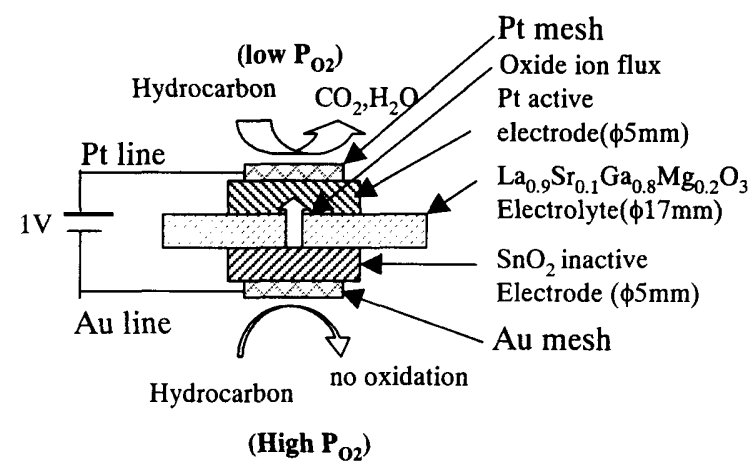

Fig. 1 Schematic view of the sensor element used. 
Table 1 Effects of electrode on the sensing property of Amperometric hydrocarbon sensor at $873 \mathrm{~K}$ and $1 \mathrm{~V}$.

\begin{tabular}{lccc}
\hline \multicolumn{1}{c}{ Electrode } & $\begin{array}{c}\text { Sensitivity } \\
\mathrm{C}_{3} \mathrm{H}_{6}\end{array}$ & $\begin{array}{c}/ \mu \mathrm{A} / \text { decay } \\
\mathrm{O}_{2}\end{array}$ & $\begin{array}{r}\text { Selectivity } \\
\mathrm{C}_{3} \mathrm{H}_{6} / \mathrm{O}_{2}\end{array}$ \\
\hline $\mathrm{SnO}_{2}-\mathrm{Pt}$ & 2.34 & 0.77 & 3.04 \\
$\mathrm{Cr}_{2} \mathrm{O}_{3}-\mathrm{Pt}$ & 74.17 & 127.30 & 0.58 \\
$\mathrm{TiO}_{2}-\mathrm{Pt}$ & 69.47 & 130.00 & 0.53 \\
$\mathrm{In}_{2} \mathrm{O}_{3}-\mathrm{Pt}$ & 48.51 & 115.80 & 0.53 \\
$\mathrm{La}_{0.6} \mathrm{Sr}_{0.4} \mathrm{CoO}_{3}-\mathrm{Pt}$ & 92.02 & 45.55 & 2.02 \\
$\mathrm{Pt}-\mathrm{Pt}$ & 3.91 & 12.91 & 0.30 \\
$\mathrm{Ag}-\mathrm{Pt}$ & 9.26 & 13.73 & 0.67 \\
$\mathrm{Au}-\mathrm{Pt}$ & 7.06 & 15.43 & 0.46 \\
$\mathrm{Ru}-\mathrm{Pt}$ & 5.96 & 11.51 & 0.52 \\
$\mathrm{Au}-\mathrm{Pt}{ }^{1}$ & 299 & 1489 & 0.20 \\
\hline
\end{tabular}

1) Result at $1073 \mathrm{~K}$.

of the LSGM disk was set to $0.5 \mathrm{~mm}$ by grinding with a diamond wheel. Platinum paste (Tanaka Kikinzoku, 7905) and commercial $\mathrm{SnO}_{2}$ (Wako, Reagent grade) were painted on each face of the prepared electrolyte with a screen-printing method at $5 \mathrm{~mm}$ in diameter. After drying, the sensor element was precalcined at $1173 \mathrm{~K}$ for 30 min. Detection characteristics of the obtained sensor were measured in a gas flow system. Air is always used as the reference gas, and $\mathrm{C}_{3} \mathrm{H}_{6}$, which is a typical hydrocarbon contained in the exhaust gas, at desirable concentration was obtained by diluting commercial $\mathrm{C}_{3} \mathrm{H}_{6}$ with air and $\mathrm{N}_{2}$, and the gas mixture was fed to the measurement chamber at $200 \mathrm{ml} / \mathrm{min}$. Pt and Au electrode were used as current collector for $\mathrm{Pt}$ and $\mathrm{SnO}_{2}$ electrode. The current through the sensor element was measured with the $\mathrm{dc}$ four-probe method and the potential of $1 \mathrm{~V}$ was generally applied to the element as is positive to Pt electrode. In this condition, Pt is expecting as active catalyst for oxidation and oxide ion is pumped to $\mathrm{Pt}$ to oxidizing hydrocarbon. Sensitivity of the sensor was defined as the current change against the one order of hydrocarbon concentration, which was denoted as decade in this study. Here it is noted that the sensor sensitivities to $\mathrm{C}_{3} \mathrm{H}_{6}$ and $\mathrm{O}_{2}$ were estimated in $\mathrm{C}_{3} \mathrm{H}_{6}$ and $\mathrm{O}_{2}$ concentration range from 500 to $2000 \mathrm{ppm}$ and $1 \%$ to $10 \%$, respectively, by extrapolating the plots.

\section{Results and Discussion}

Table 1 summarized the sensitivity to $\mathrm{C}_{3} \mathrm{H}_{6}$ and $\mathrm{O}_{2}$ on the sensor using various electrode combinations. On the large number of the electrode combinations, it was seen that the oxygen pumping current through the sensor element at $1 \mathrm{~V}$ increased with increasing $\mathrm{C}_{3} \mathrm{H}_{6}$ concentration. Therefore, the concentration of hydrocarbon can be detected on various electrode combinations. When $\mathrm{Pd}$ is used for the active electrode for oxidation, the largest sensitivity to $\mathrm{C}_{3} \mathrm{H}_{6}$ of $c a .300 \mu \mathrm{A} /$ decade was exhibited among the electrode combination examined in this study. However, sensitivity to $\mathrm{O}$ z is also extremely large when $\mathrm{Pd}$ was applied for the oxidation electrode. On the contrary, it was found that the sensitivity of the element using $\mathrm{Pt}$ and $\mathrm{SnO}_{2}$ for the active and the inactive electrodes, respectively, exhibits high selectivity to $\mathrm{C}_{3} \mathrm{H}_{6}$, while the

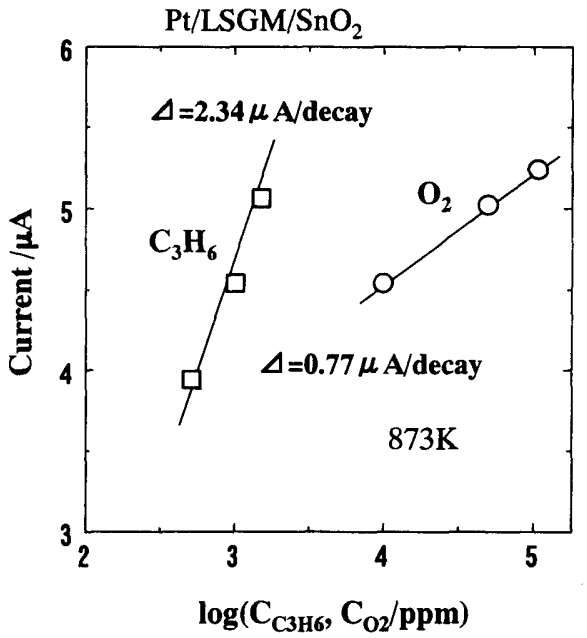

Fig. 2 Oxygen pumping current of the element as a function of $\mathrm{C}_{3} \mathrm{H}_{6}$ and $\mathrm{O}_{2}$ concentration at $873 \mathrm{~K}$. (Electrolyte; $\mathrm{La}_{0.9} \mathrm{Sr}_{0.1}$ $\mathrm{Ga}_{0.8} \mathrm{Mg}_{0.2} \mathrm{O}_{3}$, Electrode; $\mathrm{Pt}$ and $\mathrm{SnO}_{2}$ )

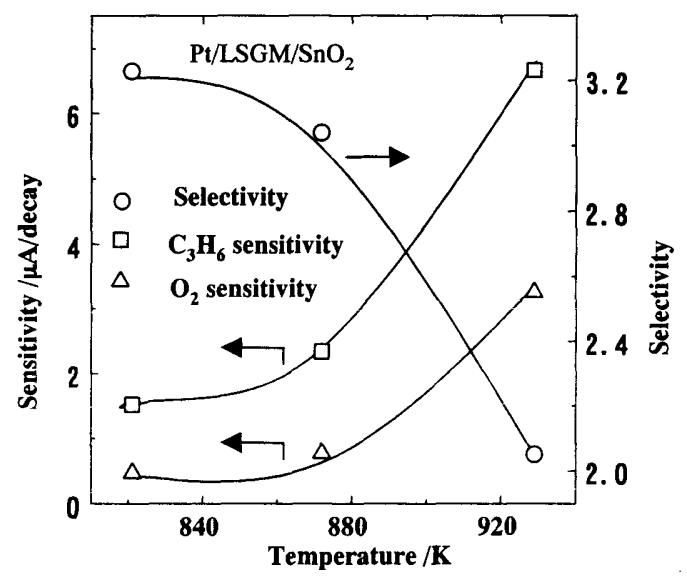

Fig. 3 Temperature dependences of the sensitivity to 1000 ppm $\mathrm{C}_{3} \mathrm{H}_{6}$ and $1 \% \mathrm{O}_{2}$ and the selectivity of the sensor.

sensitivity to $\mathrm{O}_{2}$ is not high. This might be result of a low activity to hydrocarbon oxidation and n-type semiconductivity of $\mathrm{SnO}_{2}$. Therefore, detection property of the sensor element using $\mathrm{Pt}$ and $\mathrm{SnO}_{2}$ for the active and inactive electrode, respectively, was mainly investigated in this study.

Figure 2 shows the oxygen pumping current of the element as a function of $\mathrm{C}_{3} \mathrm{H}_{6}$ and $\mathrm{O}_{2}$ concentration. It was obvious that the oxygen pumping current through the sensor element using LSGM electrolyte at the applied potential of $1 \mathrm{~V}$ increased monotonically with increasing $\mathrm{C}_{3} \mathrm{H}_{6}$ concentration, however, the current dependence on the oxygen partial pressure was not large. Therefore, it is expected that hydrocarbon can be detected by the oxygen pumping current through the element without significant interference by the coexisting oxygen. Although the conductivity of LSGM is high at $873 \mathrm{~K}$, current of few $\mu \mathrm{A}$ was observed due to a high electrical resistance of $\mathrm{SnO}_{2}$ and $\mathrm{SnO}_{2} / \mathrm{LSGM}$ interface.

Temperature dependences of sensitivity and selectivity were further studied and the results were shown in Fig.3. It is seen that the sensitivity to $\mathrm{C}_{3} \mathrm{H}_{6}$ monotonically increased with increasing operating temperature. Therefore, for the detection of hydrocarbon, it is considered 


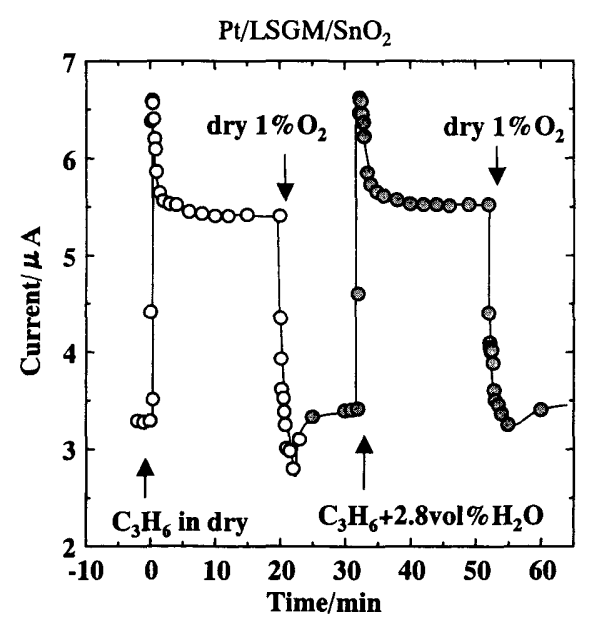

Fig. 4 Response curves against $1000 \mathrm{ppm} \mathrm{C}_{3} \mathrm{H}_{6}$ in $1 \% \mathrm{O}_{2}$ in dry $\mathrm{N}_{2}$ and that containing 3 vol\% $\mathrm{H}_{2} \mathrm{O}$ containing $\mathrm{N}_{2}$ at 873 $\mathrm{K}$. (Dry atmosphere; $1000 \mathrm{ppm}_{3} \mathrm{H}_{6}$ in $1 \% \mathrm{O}_{2}$ and balance $\mathrm{N}_{2}$, Wet atmosphere; $1000 \mathrm{ppm}_{3} \mathrm{H}_{6}$ in $1 \% \mathrm{O}_{2}, 2.8 \% \mathrm{H}_{2} \mathrm{O}$ and valance $\mathrm{N}_{2}$ ).

that the higher temperature is more desirable. However, sensitivity to $\mathrm{O}_{2}$ also increased with increasing operating temperature. This may be caused by the improved activity of the inactive electrode of $\mathrm{SnO}_{2}$ to the oxidation reaction as operating temperature increased. Therefore, the lower operating temperature is more desirable from the selectivity point of view. On the other hand, the response time was prolonged with decreasing the operating temperature. Consequently, it is considered that the optimum operating temperature exists for this sensor, and this for the present sensor is around $873 \mathrm{~K}$, which is the same temperature with that of the YSZ oxygen sensor currently used for monitoring oxygen concentration in the exhaust gas.

Exhaust gas from the internal combustion engines contains a high concentration of $\mathrm{CO}_{2}$ and $\mathrm{H}_{2} \mathrm{O}$ and these coexisting gases sometimes show a serious influence on the detection of hydrocarbon. It is seen that the oxygen pumping current against $1000 \mathrm{ppm} \mathrm{C}_{3} \mathrm{H}_{6}$ was hardly affected by coexistence of $\mathrm{CO}_{2}$ up to $10 \%$. Therefore, influence of coexisting $\mathrm{CO}_{2}$ is negligible on this sensor. Figure 4 shows the response curves against $1000 \mathrm{ppm}_{3} \mathrm{H}_{6}$ and $1 \% \mathrm{O}_{2}$ mixed with dry and 2.8 vol\% $\mathrm{H}_{2} \mathrm{O}$ containing $\mathrm{N}_{2}$. Although $\mathrm{CO}_{2}$ and $\mathrm{H}_{2} \mathrm{O}$ seem to form on the $\mathrm{Pt}$ active electrode, it is considered that the amount of $\mathrm{H}_{2} \mathrm{O}$ and $\mathrm{CO}_{2}$ is much smaller than that of added $\mathrm{H}_{2} \mathrm{O}$ and $\mathrm{CO}_{2}$. The oxygen pumping current increased quickly after exposure to $1000 \mathrm{ppm} \mathrm{C}_{3} \overline{\mathrm{H}}_{6}$ in dry atmosphere and after the over-shooting period, the current achieved the stable value. It is noted that the $90 \%$ response of this sensor is achieved within $15 \mathrm{~s}$ at $873 \mathrm{~K}$. On the other hand, after stopping the $\mathrm{C}_{3} \mathrm{H}_{6}$ feed, the current also quickly recovered to the original value. In the recovery curve, overshooting performance was also observed in a similar manner with that for the response. The $90 \%$ recovery is also achieved within $20 \mathrm{~s}$. Considering the period for exchanging the atmosphere in a measurement chamber, the response and recovery time of the sensor seem to be much faster than that of observed one. Therefore, the response and recovery time of the present amperometric sensor is reasonably fast for the application of exhaust gas monitoring. On the other hand, it is obvious that the response and recovery time as well as the current to $1000 \mathrm{ppm}$ were hardly varied by coexisting of $2.8 \mathrm{vol} \%$ $\mathrm{H}_{2} \mathrm{O}$. As a result, although the influence by change in oxygen partial pressure is slightly recognized, it can be said that coexisting $\mathrm{CO}_{2}$ and $\mathrm{H}_{2} \mathrm{O}$ hardly interferences the detection of hydrocarbons on the amperometric sensor developed in this study. Effects of hydrocarbon species on the sensitivity were also studied. The oxygen pumping current at $1 \mathrm{~V}$ was strongly dependent on the hydrocarbon species and the sensitivity increased as carbon number in hydrocarbon increases, that is almost the same tendency in the reactivity against oxidation. Among the hydrocarbons with the same carbon number, this sensor exhibited the higher sensitivity to alkene than that to alkane. In any way, developed amperometric type sensor can detect hydrocarbon selectively.

\section{Conclusion}

Although the selective detection of hydrocarbons in the exhaust gas from the internal combustion engines is one of the most difficult subjects in the field of chemical sensor, amperometric sensor using $\mathrm{La}_{0.4} \mathrm{Sr}_{0.1} \mathrm{Ga}_{0.8} \mathrm{Mg}_{0.2} \mathrm{O}_{3}$, $\mathrm{SnO}_{2}$, and $\mathrm{Pt}$ for the electrolyte, inactive and active electrodes, respectively is promising as the hydrocarbon sensor for monitoring exhaust gas. Change in oxygen pumping current upon exposure to hydrocarbons seems to be originally caused by the mixed potential, however, considering the simple potentiometric sensor, amperometric sensor shows much higher sensitivity and also wider detectable concentration.

\section{Acknowledgement}

The authors acknowledge the financial support from a grant-in-aid from the Ministry of Education, Culture, Sports, Science and Technology of Japan (No. 11102006).

\section{References}

1) K. Moriya and T. Sako, Sensors \& Actuators B, 73, 142 (2001).

2) J. H. Lee, B. K. Kim, K. Y. Lee, H. I. Kim, and K. W. Han, Sensors \& Actuators B, 59, 9 (1999).

3) G. Lu, N. Miura, and Y. Yamazoe, Sensors \& Actuators $B$, 35-36, 130 (1996).

4) R. Mukundan, E. L. Brosha, D. R. Brown, and F. H. Grazon, J. Electrochem. Soc., 147, 1583 (2000).

5) T. Hibino, Y. Kuwahara, Y. Kuroki, T. Oshima, R. Inoue, S. Kitanoya, and T. Fuma, Solid State Ionics, 104, 163 (1997).

6) T. Ishihara, H. Matsuda, and Y. Takita, J. Am. Chem. Soc., 116, 3801 (1994). 